\title{
Determinants of prostate specific antigen screening test uptake in an urban community in North-Central Nigeria
}

\author{
Jibril O Bello, Tajudeen Buhari, Taofiq O Mohammed, Hamid B Olanipekun, \\ Arinzechukwu M Egbuniwe, Olushola K Fasiku, Rasaq Wasiu
}

University of Ilorin Teaching Hospital, Ilorin, Nigeria.

\begin{abstract}
:
Background: Despite the increasing incidence of Prostate cancer, there has not been any focused screening policy or strategy in sub-Saharan Africa including Nigeria.

Objectives: To assess the level of awareness and uptake of PSA screening test and their determinants in a Nigerian community. Methods: A cross-sectional population survey of men with no prior history of prostate cancer was carried out. Logistic regression analysis was used to determine the effect of identified variables in predicting awareness and uptake of prostate cancer screening.

Results: Mean age was $51.5 \pm 9.8$ years; a few men $(31,16.9 \%)$ had ever heard of the screening test and most got the information from health centers. A low proportion $(8,4.4 \%)$ had taken the screening test. Men with incomes above poverty line $(\mathrm{OR}=11.7$ $2.8-50.1, \mathrm{p}=.001)$ or those with health insurance $(\mathrm{OR}=2.71 .2-6.5, \mathrm{p}=.023)$ were significantly more likely to be aware of the test. Only the men with higher incomes $(\mathrm{OR}=25.65 .8-114.2, \mathrm{p}=.0001)$ were significantly more likely to have taken the test.

Conclusion: Higher incomes and health insurance status impact screening awareness but only income status determines if men subsequently proceed to take the PSA screening test.

Keywords: Prostate cancer; PSA screening; sub-Saharan Africa; Nigeria.

DOI: https://dx.doi.org/10.4314/ahs.v19i1.42

Cite as: Bello JO, Bubari T, Mohammed TO, Olanipekun HB, Egbuniwe AM, Fasiku OK, et al. Determinants of prostate specific antigen screening test uptake in an urban community in North-Central Nigeria. Afri Health Sci. 2019;19(1). 1665-1670. bttps:/ / dx.doi.org/10.4314/ abs. v19i1.42
\end{abstract}

\section{Introduction}

Over the last four decades, the incidence of Prostate cancer (PCa) has been observed to be increasing in sub-Saharan African Black men. ${ }^{1-3}$ Despite this, there has not been any focused PCa screening or control policy / strategy in many of the sub-Saharan countries including Nigeria., However, prostate specific antigen (PSA) screening tests are increasingly available in many urology clinics though

\section{Corresponding author: \\ Jibril O Bello, University of Ilorin Teaching Hospital, Ilorin, Nigeria \\ Email: jabarng@yahoo.com}

many primary and secondary care centers still lack access to the test. The decision to proceed to screening tests for a Nigerian man typically follows a subject-physician discussion on the subject's PCa risk and then shared decision process between the subject and the physician/urologist. Whenever this interaction occurs, Nigerian men seem to display strong willingness to undergo screening especially when no or very minimal costs are involved. ${ }^{4}$ Never-the-less, widely-reported observations of a lack of awareness of and poor uptake of PSA screening among Nigerian men (and other sub-Saharan African men) compared with most of the rest of the world continues to be made. ${ }^{5}$ In general, baseline cancer awareness and awareness of cancer screening tests is less than $40 \%$ and $20 \%$ respectively in at-risk populations of sub-Saharan Afri- 
ca. $^{5}$ A probable consequence of this challenge to cancer care and control is the very high incidence of late presentations with advanced disease and a high mortality from the disease..$^{5-7}$ Generally, it is thought that the low uptake of cancer screening opportunities may be related to barriers to accessing health care and weak health systems in most parts of sub-Saharan Africa., ${ }^{5,8}$ PCa remains the most commonly diagnosed male cancer in Nigerian men and the vast majority of presentations are at late incurable stage. ${ }^{9,10}$ There is thus an urgent need to evaluate the specific determinants of low awareness and poor uptake of PCa screening (PSA test). This would provide evidence-based guides to policy makers and allow targeted interventions to improve the awareness and uptake of PCa screening test. This study was conducted in Nigerian men, the largest population of native African black men, to assess the determinants of awareness and uptake of PCa screening tests.

\section{Material and methods}

This was a cross-sectional population survey conducted in Ilorin, North-Central Nigeria over a 3-month period (July - September) in 2016. The target population were 40 to 70 -year-old men with no prior history of PCa. Based on an assumption that the anticipated population proportion of PSA screened males is unlikely to exceed $10 \% ; 3,11$ ${ }^{13}$ the estimated minimum sample size required for a $5 \%$ degree of precision and at 95\% confidence interval was determined to be 138 . We included a $30 \%$ increase over our calculated sample size to account for incomplete/ ineligible responses. These men were recruited by convenient sampling from work places, markets and bus stations by trained interviewers. Only consenting men who fulfilled the inclusion criteria and volunteered to complete the questionnaire were included in the study. Study participants were requested to fill a structured questionnaire which included demographic questions, health insurance status, awareness of prostate cancer and its screening, family history of prostate cancer, and history of previous prostate cancer screening. Information on income levels that were collected were grouped based on the 2015
World Bank defined absolute poverty line of $\$ 1.90 /$ day. Potential personal identifiers were removed from data obtained from subjects to maintain confidentiality.

Data was entered and analyzed using the Statistical Package for the Social Sciences (SPSS, Inc., Chicago, IL, USA) version 21. Characteristics of the study population were summarized by means \pm standard deviation and counts $(\%)$. Logistic regression analysis was used to explore the effect of subjects' characteristics in predicting awareness and uptake of prostate cancer screening. The level of significances used was $\mathrm{p}<0.05$. The study was approved by the Ethical and Review Committee of University of Ilorin Teaching Hospital, Nigeria and written informed consent was obtained from all the recruited subjects.

\section{Results}

One hundred and eighty-three men consented to the study and adequately completed the questionnaires for analysis, response rate being $96 \%$. Mean age was $51.5 \pm 9.8$ years and one-quarter of the respondents had incomes below what World Bank defined absolute poverty; about three-quarters had secondary education or more and a similar proportion had no health insurance (Table 1). Only half of respondents in this study $(92,50.3 \%)$ had ever heard of PCa and a smaller proportion $(31,16.9 \%)$ had ever heard of the PSA screening test. For men who had heard of PSA screening, the main source of the health information was from health centers $(17,54.8 \%)$; others got the information from newspapers $(3,9.7 \%)$, online $(5$, $16.1 \%)$ and other mass media sources $(6,19.4 \%)$.

We found that only a few men $(13,7.1 \%)$ had ever had the PSA test done and five of these men had the PSA test done in the last 12 months. Of respondents who had a PSA test done, only eight $(4.4 \%)$ had the tests for screening purposes with the remainder done to evaluate urinary symptoms. Majority of the men $(167,91.3 \%)$ had never had rectal or prostate examination. Although one-fifth of the men $(40,21.9 \%)$ knew of men with PCa, only a few $(5,2.7 \%)$ had a history of PCa in a close male relative (father, brother or uncle). 
Table 1: Demographic characteristics of respondents

\begin{tabular}{lll}
\hline Subjects' characteristics & $\mathrm{n}(\%)$ & Mean \pm SD \\
\hline Age & & $51.5 \pm 9.8$ \\
Education level & $5(2.7)$ & \\
none & $22(12.0)$ & \\
primary & $49(26.8)$ & \\
secondary & $107(58.5)$ & \\
tertiary & & \\
*Income level & $47(25.7)$ \\
below poverty line & $136(74.3)$ \\
above poverty line & & \\
Marital status & $5(2.7)$ & \\
unmarried & $175(95.6)$ & \\
married & $2(1.0)$ & \\
divorced & $1(0.5)$ & \\
others & $133(72.7)$ & \\
Health insurance status & $50(27.3)$ & \\
not insured & \\
Insured &
\end{tabular}

*income level grouped based on 2015 World Bank defined absolute poverty line (\$1.90)

On univariate logistic regression, men with incomes above the 2015 World Bank poverty line $(\mathrm{OR}=11.8$ 2.8-50.4, $\mathrm{p}=0.001)$, tertiary educated men $(\mathrm{OR}=3.5$ 1.4-9.0, $\mathrm{p}=0.009)$, or those who had health insurance coverage $(\mathrm{OR}=3.71 .7-8.3, \mathrm{p}=0.001)$ were significantly more likely to be aware of the PSA test than those below the poverty line, less educated or without health insurance respectively (Table 2). However, on multivariate analysis only the poverty status $(\mathrm{OR}=11.72 .8-50.1, \mathrm{p}=$ $0.001)$ and health insurance status $(\mathrm{OR}=2.71 .2-6.5, \mathrm{p}$ $=0.023$ ) remained statistically significant (Table 2 ). With regards to the likelihood of having had a PSA test done, men with incomes above the poverty line $(\mathrm{OR}=25.8$ 5.8-114.9, $\mathrm{p}=0.0001)$ and those with health insurance $(\mathrm{OR}=3.51 .1-10.8, \mathrm{p}=0.034)$ were significant more likely than those with incomes below the poverty line or those without insurance respectively; there was also no significant difference between tertiary educated men and those with less education with regards to likelihood to have had a PSA test on univariate analysis (Table 2). On multivariate analysis, only the poverty status $(\mathrm{OR}=25.6$ 5.8-114.2, $\mathrm{p}=0.0001)$ remained a statistically significant predictor of uptake of PSA testing. 
Table 2: Univariate and multivariate regression analysis of potential predictors of awareness of the PSA test and likelihood of having had a PSA test

\begin{tabular}{lllllll}
\hline Predictors & $\begin{array}{l}\text { Univariate } \\
\text { OR }\end{array}$ & $95 \% \mathrm{Cl}$ & $\mathrm{P}$ & $\begin{array}{l}\text { Multivariate } \\
\text { OR }\end{array}$ & $95 \% \mathrm{Cl}$ & $\mathrm{p}$ \\
\hline PSA test awareness & & & & & & \\
age & 0.9 & $0.9-1.1$ & 0.709 & & & \\
married & 0.5 & $0.1-2.7$ & 0.416 & & & \\
*above poverty line & 11.8 & $2.8-50.4$ & $0.001^{\dagger}$ & 11.7 & $2.8-50.1$ & $0.001^{\dagger}$ \\
insured men & 3.7 & $1.7-8.3$ & $0.001^{\dagger}$ & 2.7 & $1.2-6.5$ & $0.023^{\dagger}$ \\
tertiary educated & 3.5 & $1.4-9.0$ & $0.009^{\dagger}$ & 2.3 & $0.8-6.3$ & 0.107 \\
PSA test uptake & & & & & \\
age & 1.0 & $0.9-1.1$ & 0.757 & & & \\
married & 1.0 & $0.1-4.2$ & 0.982 & & & \\
*above poverty line & 25.8 & $5.8-114.9$ & $0.000^{\dagger}$ & 25.6 & & \\
insured men & 3.5 & $1.1-10.8$ & $0.034^{\dagger}$ & 1.5 & $0.4-6.2$ & 0.604 \\
tertiary educated & 2.5 & $0.7-9.3$ & 0.180 & & & \\
\hline
\end{tabular}

${ }^{*}$ World Bank absolute poverty line $(\$ 1.90),{ }^{\dagger}$ significant

\section{Discussion}

Evidence abound that PCa is the most commonly diagnosed cancer in Nigerian men; 5,14 despite this, there are no focused health policies or strategies for PCa screening or control programs in Nigeria. Unlike most other countries with significant PCa burdens, population screening never took hold in Nigeria. Recent recommendations now advocate for individualized screening which is somewhat the way PSA screening test is now administered in Nigeria though without any coordination and/or strategy.

It has been observed that PCa screening awareness and uptake of the PSA test are abysmally low in the country and this study further confirms these observations. ${ }^{13,15,16}$ We found that only $16.9 \%$ of respondents were aware of the PSA screening test which is fairly similar to the $13.7 \%$ found in a study of out-patient clinic attendees carried out in South-West Nigeria. ${ }^{13}$ Oranusi and colleagues however found a much higher level of awareness of 56.8\% in their study of 20 to 69 year-old male public servants in South-East Nigeria; ${ }^{11}$ this may be due to a wider age range study sample and selection of only employed public servants.

Though we found that $7.1 \%$ of respondents in our study had at least one PSA test conducted only a dismal 4.4\% had the test done in the context of PSA screening. The level of test uptake found in our study is lower than the $6.4 \%$ found in South-East Nigerian survey of public servants, the $8.2 \%$ found in a South-West Nigerian single center hospital-based study and much lower than the $17.1 \%$ found in a survey of men participating in a health screening program in a large Nigerian city. ${ }^{11,13,16}$ The higher values seen in these studies may be the result of a selection bias inherent in the evaluation of only male public servants, similar bias often seen in hospital-based study of ill patients and the bias related to the potentially better health seeking behaviour of attendees of a health screening program respectively. Similar studies in the West African sub-region revealed similar values to this index study with the PSA screening uptake in Ghana and Senegal being $2.5 \%$ and $3 \%$ respectively., We believe that our population survey of 'at risk' men potentially provides a more accurate value of the uptake of PCa screening/PSA testing in Nigerian men though we acknowledge that with the self-report nature of the data and the consequent possible provision of socially acceptable responses by some respondents, the true value may even be lower.

Perhaps of greater importance are the determinants of the observed poor awareness and poor uptake of PSA screening test; this study, to the best of our knowledge, is the first to evaluate this important knowledge gap in the West African sub-region. We found that poverty and a 
lack of health insurance negatively impacted being aware of the PSA screening test significantly. Our findings are similar to that of a North American survey which found that annual visits to a doctor, higher educational levels, and greater take-home pay were significantly related to the awareness of the PSA screening test. ${ }^{17}$ These findings may be because men with health insurance coverage are generally able to pay more frequent visits to points of health care without incurring catastrophic health-related expenditures and they potentially have increased access to health information which can impact their awareness of PSA screening tests. It is also thought that unaffordable out-of-pocket costs required to pay a visit to a health care center for poor individuals without health insurance prevents them from accessing health information including those about screening. The mass media has not been effectively deployed in disseminating health information on PSA screening in Nigeria and this study found that most men got information about PSA screening through contact with health personnel in health care centers. Deploying the mass media can be very effective as recently demonstrated during the control of the Ebola pandemic in Nigeria. ${ }^{18}$

We found that poverty and a lack of health insurance significantly impacted the uptake of PSA screening test negatively. Surprisingly, we found no significant relationship between being well educated and accepting to have the PSA test. This may be related to the high unemployment rate in the region and that having tertiary education does not necessarily mean an ability to earn high incomes as many are under-employed, under-paid or outright unemployed. Thus the ability to afford the test plays the more important role in test uptake. Our findings are similar to results from a study of African American men which revealed that income levels and health insurance status but not educational level were determinants of uptake of PSA screening tests. ${ }^{19}$ A study which queried the 2013 Namibia Demographic and Health Survey found that older men, higher income, secondary education or higher and men with health insurance were more likely to undergo screening for $\mathrm{PCa} .{ }^{8}$ They also found that effect of health insurance status remained robust even after controlling for demographic and socio-economic variables. ${ }^{8}$ This finding is most probably related to the well-known disparities in health care utilization among individuals with or without health insurance. However, we found on multivariate analysis that only the poverty status and not health insurance status remained statistically significant. We believe this may be the consequence of poor health insurance coverage levels and critically - the non-inclusion of cancer screening programs and tests in the country's health insurance scheme. ${ }^{5}$ Out-of-pocket expenditures thus remains the major means of getting screened and only men with higher incomes can afford it.

This study has some limitations which include its cross-sectional design. This makes it difficult to establish a causal relationship between poverty or health insurance status and PSA screening awareness or test uptake. We are unable to conclude, for instance, if men with health insurance or higher incomes are more likely to be aware of PSA screening or whether the men who are aware of PSA screening are more likely to seek out health insurance or funds. Another limitation is the self-report nature of the data and the possible introduction of the bias of provision of socially acceptable responses by some respondents; the study could not physically validate the responses of respondents with medical records. Neverthe-less this study sheds light on the important issue of determinants of poor awareness and poor uptake of PSA screening test. It provides an evidence-based guide to national or regional policymakers and interventionists that policies that focus on improving education, incomes and health insurance coverage levels could lead to increases in awareness and uptake of PSA screening tests. Decentralization of PSA screening health information to involve the mass media in more significant roles may also improve awareness and uptake levels.

\section{Conclusion}

Nigerian men with incomes higher than the World Bank defined absolute poverty line and those with health insurance cover have greater awareness of PSA screening tests than men below the poverty line or without health insurance. Only the poverty status of these 'at risk' men determines if they will proceed to take the PSA screening test with men above the poverty line more likely to have PSA screening tests. This study provides evidence-based guide that policies focused on improving health insurance coverage and incomes could improve awareness and uptake of PSA screening test. 


\section{Conflict of interest}

The authors declare that there are no conflicts of interest.

\section{Funding}

This study was entirely funded by the authors.

\section{Acknowledgements}

None.

\section{References}

1. Adeloye D, David RA, Aderemi AV, et al. An Estimate of the Incidence of Prostate Cancer in Africa: A Systematic Review and Meta-Analysis. PLoS One. 2016;11(4):e0153496

2. Rebbeck TR, Devesa SS, Chang B-L, et al. Global Patterns of Prostate Cancer Incidence, Aggressiveness, and Mortality in Men of African Descent. Prostate Cancer. 2013; 2013:560857

3. Chu LW, Ritchey J, Devesa SS, Quraishi SM, Zhang $\mathrm{H}$, Hsing AW. Prostate cancer incidence rates in Africa. Prostate Cancer. 2011; 2011:947870

4. Akinremi TO, Adeniyi A, Olutunde A, Oduniyi A, Ogo $\mathrm{CN}$. Need for and relevance of prostate cancer screening in Nigeria. E Cancer Medical Science. 2014; 8:457

5. Morhason-Bello IO, Odedina F, Rebbeck TR, et al. Challenges and opportunities in cancer control in Africa: a perspective from the African Organisation for Research and Training in Cancer. Lancet Oncol. 2013 Apr;14(4):e142-51

6. Zeigler-Johnson CM, Rennert H, Mittal RD, et al. Evaluation of prostate cancer characteristics in four populations worldwide. Can J Urol. 2008; 15(3):4056-64

7. Bello JO. Predictors of survival outcomes in native sub Saharan black men newly diagnosed with metastatic prostate cancer. BMC Urology. 2017; 17:39

8. Kangmennaang J, Mkandawire P, Luginaah I. What Prevents Men Aged 40-64 Years from Prostate Cancer Screening in Namibia? J. Cancer Epidemiol. 2016; 2016:7962502
9. Badmus TA, Adesunkanmi AR, Yusuf BM, et al. Burden of prostate cancer in SouthWestern Nigeria. Urology. 2010; 76(2):412-6

10. Agalliu I, Adebiyi AO, Lounsbury DW, et al. The feasibility of epidemiological research on prostate cancer in African men in Ibadan, Nigeria. BMC Public Health. 2015;15:425

11. Oranusi CK, Mbieri UT, Oranusi IO, Nwofor AME. Prostate cancer awareness and screening among male public servants in Anambra State, Nigeria. Afr J Urol 2012; 18:72-4. PubMed.

12. Jalloh M, Zeigler-Johnson C, Sylla-Niang M, et al. A study of PSA values in an unselected sample of Senegalese men. Can J Urol. 2008; 15(1):3883-5. PubMed.

13. Ogundele SO, Ikuerowo SO. A Survey of the Awareness of Prostate Cancer and its Screening among Men Attending the Outpatient Clinics of a Tertiary Health Center in Lagos, Nigeria. Niger J Surg. 2015; 21(2): 115-8 14. Ogunbiyi JO, Shittu OB. Increased incidence of prostate cancer in Nigerians. J Natl Med Assoc. 1999; 91(3):159-64

15. Enaworu OU, Khutan R. Factors influencing Nigerian men's decision to undergo prostate specific antigen testing. Afri Health Sci. 2016;16(2): 524-32.

16. Olapade-Olaopa EO, Owoaje ET, Kola L, Ladipo MM, Adebusoye L, Adedeji TG. Knowledge and perception of Nigerian men 40 years and above regarding prostate cancer. J West Afr Coll Surg. 2014; 4(1):1-16

17. Obana M, O'Lawrence H. Prostate cancer screening: PSA test awareness among adult males. J Health Hum Serv Adm. 2015;38(1):17-43.

18. Akpobo O. Mass media health communication: imperative for sustainable health development in Nigeria. Mgbakoigba: J Afr Studies. 2015; 4: 1-6. PubMed.

19. Dean LT, Subramanian SV, Williams DR, Armstrong K, Charles CZ, Kawachi I. Getting Black Men to Undergo Prostate Cancer Screening: The Role of Social Capital. Am J Mens Health. 2015; 9(5): 385-96. 